\title{
Retroperitoneal neurilemmoma with cystic degeneration mimicking hydatid cyst
}

\author{
Manash Ranjan Sahoo, Anil Kumar T
}

\begin{abstract}
Introduction: Retroperitoneal neurilemmoma is a common tumor in an uncommon place. If secondary changes occur in the tumor, it becomes very difficult to diagnose by clinical and radiological examination. In this case report, we have shown how a neurilemmoma with cystic degeneration was misdiagnosed as hydatid cyst till it was confirmed by histopathology. Case Report: A 30-year-old female presented with pain on right side of abdomen since one month. Clinical examination revealed firm mass of $8 \times 10 \mathrm{~cm}$ in right hypochondriac and lumbar region. Radiological examination showed it as complex cystic lesion with multiple membrane probably hydatid cyst. With preoperative diagnosis as hydatid cyst laparoscopy revealed cystic lesion with degenerated cheesy tissue then by opening the abdomen by sub costal incision deroofing of the cyst was done. Histopathological examination confirmed it as neurilemmoma. Schwannomas have true capsules composed of epineurium. Although target and fascicular signs are characteristic radiological features of schwannoma, these are not frequently seen in retroperitoneal schwannomas. In the absence of typical signs, diagnosing a retroperitoneal schwannoma is difficult when using cross-
\end{abstract}

Manash Ranjan Sahoo ${ }^{1}$, Anil Kumar $\mathrm{T}^{2}$

Affiliations: ${ }^{1} \mathrm{MS}$, Associate Professor, Department of Surgery, S.C.B. Medical College, Cuttack, Odisha, India; ${ }^{2}$ Post Graduate, Department of Surgery, S.C.B. Medical College, Cuttack, Odisha, India.

Corresponding Author: Dr. Manash Ranjan Sahoo, Mailing Address: Orissa Nursing Home, Medical road, Ranihat, Cuttack, Odisha, India - 753007; Ph: +919937025779; Fax: 0671-2414034; Email: manash67@gmail.com

Received: 27 October 2012

Accepted: 18 February 2012

Published: 01 October 2013 sectional imaging alone. Conclusion: A retroperitoneal schwannoma is a rare disorder and most cases are benign for which enucleation is curative. Secondary changes can misdiagnose the cases both clinically and radiologically and one should be aware of it.

Keywords: Retroperitoneum, Hydatid cyst, Neurilemmoma, Cystic degeneration

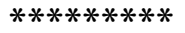

Sahoo MR, Anil Kumar T. Retroperitoneal neurilemmoma with cystic degeneration mimicking hydatid cyst. International Journal of Case Reports and Images 2013;4(10):571-574.

$* * * * * * * * *$

doi:10.5348/ijcri-2013-10-382-CR-11

\section{INTRODUCTION}

Schwannomas are nerve sheath tumors, usually found in the head, neck and on the flexor surfaces of the extremities. They are believed to be benign tumors with female predominance occurring between $2-5$ decade $[1$, 2], with few cases of malignant transformation reported. Schwannomas are rarely found in the retroperitoneal cavity [3, 4], only about $0.3-3.2 \%$ [7]. Pathologically, it is a well-encapsulated lesion [5] demonstrating specific Antoni A/B areas. Characteristic immunochemical features are a positive $\mathrm{S}-100$ [6] and a negative CD-34. In this report, we aimed to illustrate how cystic degenerated neurilemmoma was misdiagnosed hydatid cyst based on radiological imaging.

\section{CASE REPORT}

A 30-year-old female presented with pain on right side of abdomen since a month. Clinical examination revealed 
a firm mass of $8 \times 10 \mathrm{~cm}$ in the right hypochondrium and lumbar region. Routine hemogram was normal and liver function test was normal.

Ultrasound revealed well defined heterogeneous lesion with multiple membrane, solid cystic portion with internal echoes, of size $12.4 \times 7 \mathrm{~cm}$ in sub hepatic space probably hydatid cyst.

Computed tomography (CT) scan revealed a large well defined circumscribed oval complex cystic mass lesion in right hypochondrium and lumbar region abutting right lobe of liver and right kidney (Figure 1).

On the operation table laparoscopy showed cystic mass (Figure 2). With preoperative diagnosis of hydatid cyst, aspiration revealed straw colour fluid at the beginning with cheesy material with hydatid cannula (Figure 3 ). Deroofing of the cyst was done (Figure 4). Later frank blood started coming which could not be controlled (Figure 5), so abdomen was opened by right sub costal incision. Whole of the cyst cannot be removed since its close proximity to inferior vena cava and duodenum, however, most of the cyst wall was removed. Hemostasis

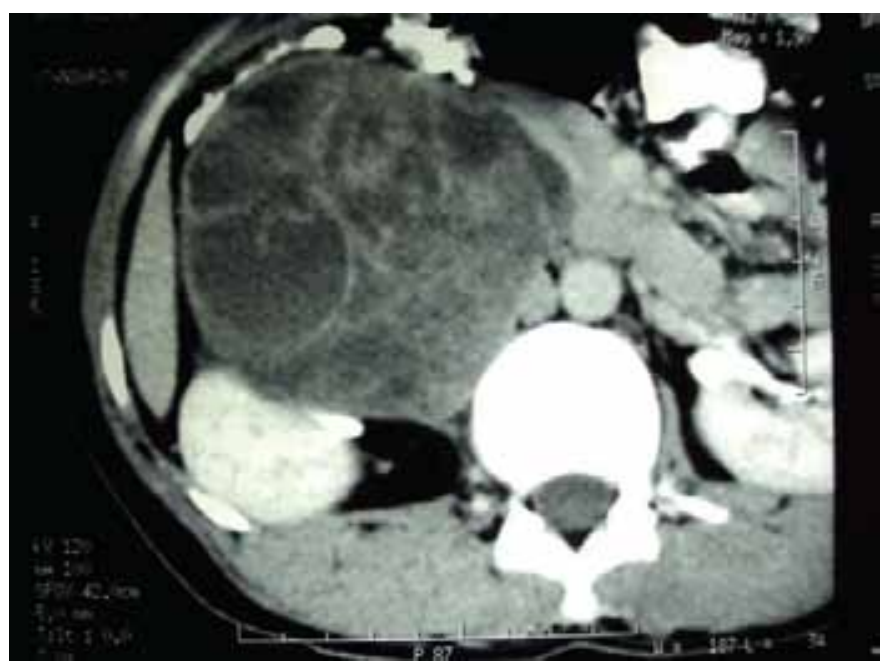

Figure 1: Computed tomography scan showing retroperitoneal cyst with multiple septation may be hydatid cyst abutting liver.

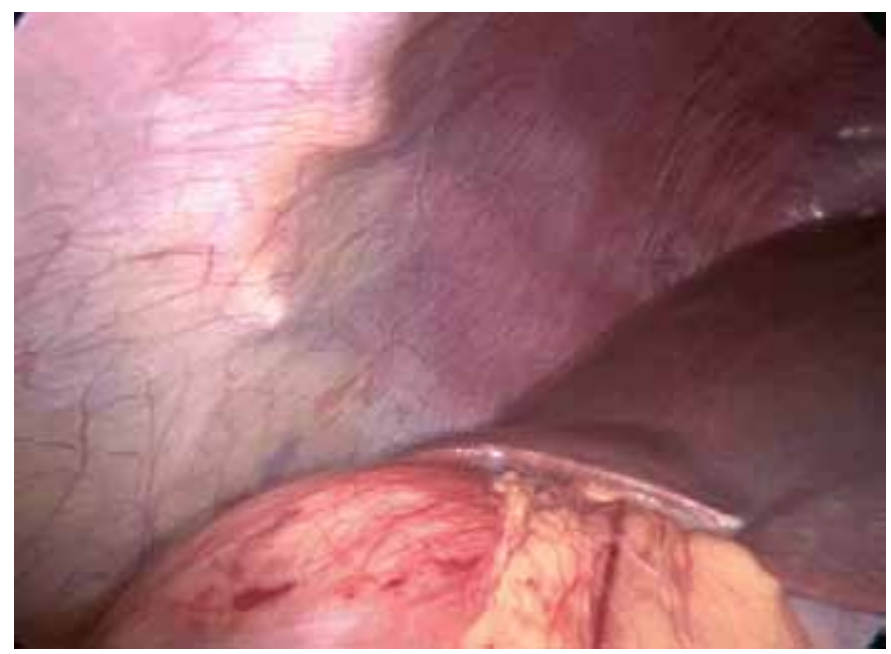

Figure 2: Intracorporeal laparoscopic view of cyst.

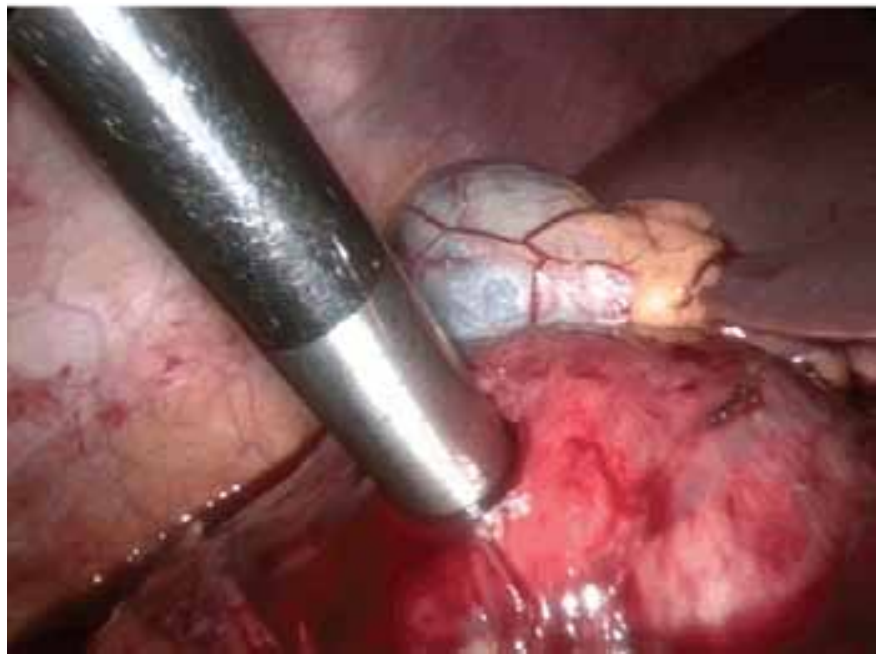

Figure 3: Suction of contents of the cyst using hydatid cannula.

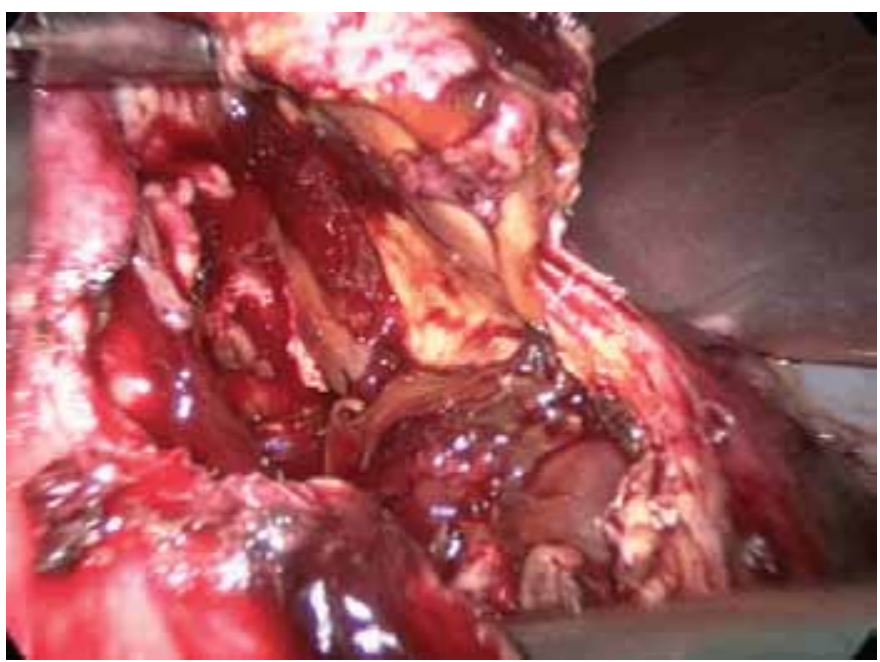

Figure 4: Deroofing of the cyst.

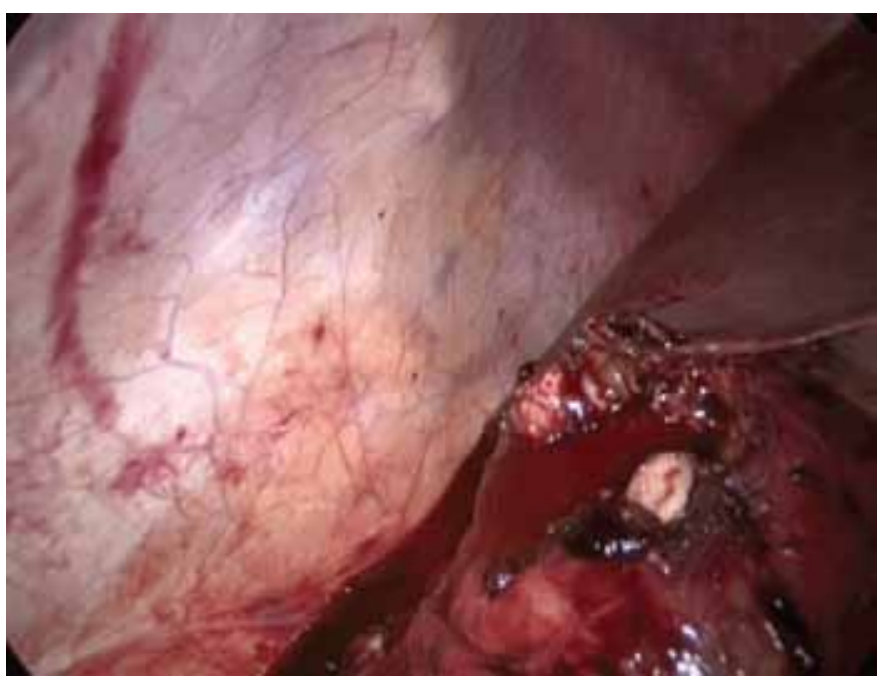

Figure 5: Oozing started from the redundant cyst, hence converted to open method. 
achieved by placing a ribbon pack which was removed three days postoperatively. Postoperative period was uneventful.

A week later histopathological examination came out as benign neurilemmoma. No recurrence of the cyst or no symptoms were noted after following-up patient for a period of eight months.

\section{DISCUSSION}

Schwannomas (neurilemmoma) are nerve sheath tumors that usually affect the head, neck and the flexor surfaces of the extremities. It is rare to find a schwannoma in the retroperitoneal cavity $[3,4]$ accounts for $0.3-3.2 \%$ of schwannomas [7]. They usually affect adult patients aged 20-50 years and females are more frequently affected than males $[1,2]$.

Schwannomas have true capsules composed of epineurium [5]. The tumor mass is characteristically eccentricwithrespecttotheaffectednerve. Retroperitoneal schwannomas show cystic degeneration in up to $60 \%$ of cases while calcification is seen in $23 \%$ of cases only. These changes make diagnosis even more difficult. Although target and fascicular signs are characteristic radiological features of schwannoma, these are not frequently seen in retroperitoneal schwannomas. In the absence of typical signs, diagnosing a retroperitoneal schwannoma is difficult when using cross-sectional imaging alone. Computed tomography and ultrasonography should be used to guide tissue biopsies and identify the aggressive features of a malignant schwannoma, which account for about $1 \%$ of retroperitoneal schwannomas. Schwannomas are encapsulated tumors [5]. Microscopically, they demonstrate Antoni A areas (densely cellular, arranged in short bundles or interlacing fascicles) and Antoni B areas (fewer cells, organized, with great myxoid component). They are positive for S-100 [6] and negative for CD-34. Detecting a malignant retroperitoneal schwannoma is crucial for effective management as these carry a much poorer prognosis. Its clinical, radiological, and histological features usually clinch the diagnosis. Radiologically, a malignant schwannoma has irregular margins and infiltrates the adjacent structures. Distant metastases via perineural and intra-neural routes are characteristic features. Histologically, an infiltrative margin with nuclear palisading is a striking feature. In terms of treatment, surgery is the modality of choice for retroperitoneal schwannomas. Chemotherapy and radiotherapy have only limited roles. In malignant schwannomas, adjuvant chemotherapy or radiotherapy has marginal added benefit; some authors advocate induction chemotherapy for this condition. Our patient had benign neurilemmoma with already cystic degeneration which could not be removed fully due to severe hemorrhage and close proximity to duodenum and inferior vena cava. Postoperatively patient was closely followed-up for a period of eight months which revealed no recurrence of disease which might have been due to degeneration that had already set in.

\section{CONCLUSION}

Retroperitoneal schwannoma is a rare disorder and most cases are benign for which enucleation is curative. Secondary changes can misdiagnose the cases both clinically and radiologically and one should be aware of it.

$* * * * * * * * *$

\section{Author Contributions}

Manash Ranjan Sahoo - Conception and design, Acquisition of data, Analysis and interpretation of data, Drafting the article, Final approval of the version to be published

Anil Kumar T - Conception and design, Acquisition of data, Analysis and interpretation of data, Drafting the article, Critical revision of the article, Final approval of the version to be published

\section{Guarantor}

The corresponding author is the guarantor of submission.

\section{Conflict of Interest}

Authors declare no conflict of interest.

\section{Copyright}

(C) Manash Ranjan Sahoo et al. 2013; This article is distributed under the terms of Creative Commons attribution 3.0 License which permits unrestricted use, distribution and reproduction in any means provided the original authors and original publisher are properly credited. (Please see www.ijcasereportsandimages.com/ copyright-policy.php for more information.)

\section{REFERENCES}

1. Enzinger FM, Weiss SM. Soft tissue tumors, St. Louis: Mosby, 1983: 5-7.

2. Schindler SO, Dixon JH, Case P. Retroperitoneal giant schwannomas: Report of two cases and review of the literasture. J Orthopeadic Surg. 2002; 10: 77-84

3. Maleux G, Brys P. Sampson I, Sciot R, Baert AL. Giant schwannoma of the lower leg. Eur. Radio. 1997; 7:1031-34.

4. Gubbay AD, Moschille G, Gray BN, Thompson I. Retroperitoneal schwannoma: A case series and review. ANZ J Surg. 1995; 65: 197-200.

5. Guz BV, Wood DP Jr, Montie JE, Pontes JE. Retroperitoneal nerve sheath tumors: Cleveland clinic experience. J Urol. 1989; 142: 1434-7.

6. Harkin I. Pathology of nerve sheath tumors. Ann NY Acad Sci. 1986; 486: 147-54. 
7. Melicow MM. Primary tumors of the retroperitoneum: A clinicopathologic analysis of 162 cases: Review of the literature and tables of classification. $J$ Int Coll Surg 1953; 19: 401-49.

Access full text article on other devices

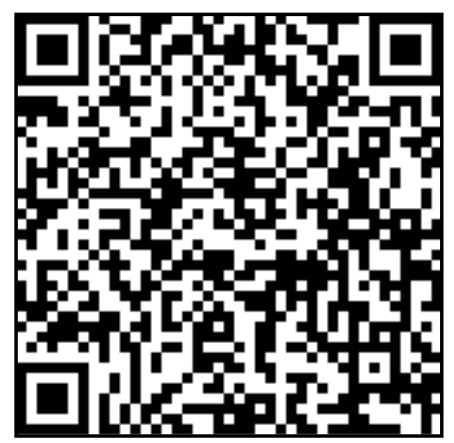

Access PDF of article on other devices

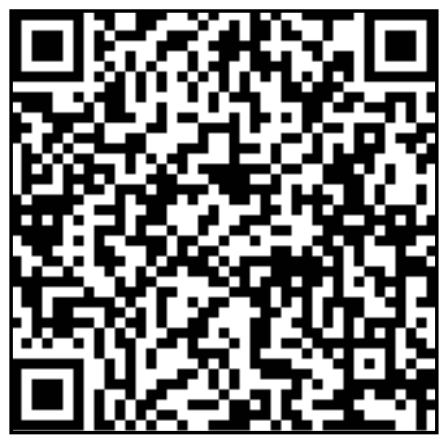

